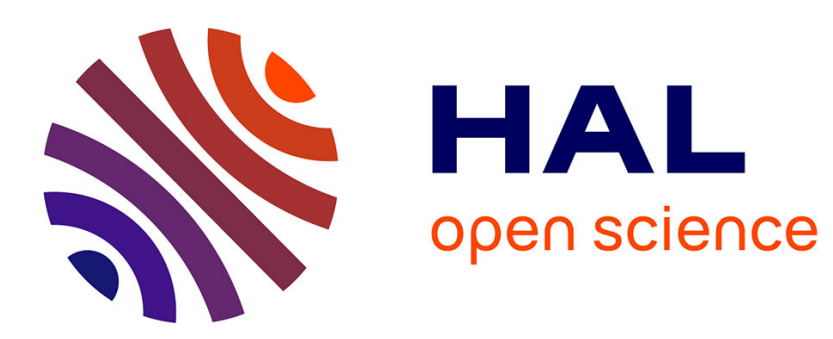

\title{
Pattern formation in the ferrocyanide-iodate-sulfite reaction: The control of space scale separation
}

\author{
Istvan Szalai, Patrick de Kepper
}

\section{To cite this version:}

Istvan Szalai, Patrick de Kepper. Pattern formation in the ferrocyanide-iodate-sulfite reaction: The control of space scale separation. Chaos: An Interdisciplinary Journal of Nonlinear Science, 2008, 026105 (18), pp. 1-9. 10.1063/1.2912719 . hal-00617252

\section{HAL Id: hal-00617252 https://hal.science/hal-00617252}

Submitted on 26 Aug 2011

HAL is a multi-disciplinary open access archive for the deposit and dissemination of scientific research documents, whether they are published or not. The documents may come from teaching and research institutions in France or abroad, or from public or private research centers.
L'archive ouverte pluridisciplinaire HAL, est destinée au dépôt et à la diffusion de documents scientifiques de niveau recherche, publiés ou non, émanant des établissements d'enseignement et de recherche français ou étrangers, des laboratoires publics ou privés. 


\title{
Pattern formation in the ferrocyanide-iodate-sulfite reaction: The control of space scale separation
}

\author{
István Szalai ${ }^{1}$ and Patrick De Kepper ${ }^{2}$ \\ ${ }^{1}$ Institute of Chemistry, L. Eötvös University, P. O. Box 32, H-1518 Budapest 112, Hungary \\ ${ }^{2}$ Centre de Recherche Paul Pascal, CNRS, University of Bordeaux I, 115, Avenue Dr. A. Schweitzer, \\ F-33600 Pessac, France
}

(Received 7 February 2008; accepted 31 March 2008; published online 27 June 2008)

\begin{abstract}
We revisit the conditions for the development of reaction-diffusion patterns in the ferrocyanideiodate-sulfite bistable and oscillatory reaction. This hydrogen ion autoactivated reaction is the only example known to produce sustained stationary lamellar patterns and a wealth of other spatiotemporal phenomena including self-replication and localized oscillatory domain of spots, due to repulsive front interactions and to a parity-breaking front bifurcation (nonequilibrium Ising-Bloch bifurcation). We show experimentally that the space scale separation necessary for the observation of stationary patterns is mediated by the presence of low mobility weak acid functional groups. The presence of such groups was overlooked in the original observations made with hydrolyzable polyacrylamide gels. This missing information made the original observations difficult to reproduce and frustrated further experimental exploitation of the fantastic potentialities of this system. Using one-side-fed spatial reactors filled with agarose gel, we can reproduce all the previous pattern observations, in particular the stationary labyrinthine patterns, by introducing, above a critical concentration, well controlled amounts of polyacrylate chains in the gel network. We use two different geometries of spatial reactors (annular and disk shapes) to provide complementary information on the actual three-dimensional character of spatial patterns. We also reinvestigate the role of other feed parameters and show that the system exhibits both a domain of spatial bistability and of large-amplitude $p \mathrm{H}$ oscillations associated in a typical cross-shape diagram. The experimental method presented here can be adapted to produce patterns in the large number of oscillatory and bistable reactions, since the iodate-sulfite-ferrocynide reaction is a prototype of these systems.

(c) 2008 American Institute of Physics. [DOI: 10.1063/1.2912719]
\end{abstract}

In a large variety of natural and artificial systems, the development of spatial structures results from the interplay of nonlinear processes operating on different time and length scales. Chemical processes commonly proceed through competing sequences of elementary steps that operate at very different rates and may involve species with very different molecular weights, thus with eventual different diffusion coefficients in solution. Accordingly, nonlinear chemical reaction-diffusion systems naturally serve as paradigms for nonequilibrium self-organization phenomena. In particular, they are often thought to offer simplified versions of time and space patterning mechanisms at work in biological systems. ${ }^{1-6}$ Reactions leading to such patterning phenomena rely on competing chemical activation and inhibition kinetic pathways. ${ }^{4-6}$ During the past three decades, more than a dozen families of aqueous solution reactions, with hundreds of variants, were discovered to have the above required kinetic properties. ${ }^{6}$ In well stirred solutions, these reactions can lead to steady-state multiplicity, periodic, or chaotic oscillations when they operate far from their thermodynamic equilibrium. ${ }^{4,6}$ These phenomena and the underlying instabilities at their origin are currently well documented. ${ }^{3}$ In parallel, there has also been progress in the associated experimental problem of the formation of chemical spatial patterns through reaction-diffusion instabilities, but in a more limited way. Following the advancement of open spatial reactors, in which the reaction processes could be maintained at a controlled distance from thermodynamic equilibrium, sustained traveling-wave patterns have been observed in an increasing number of different reactions. ${ }^{7-13}$ Beside waves, the spontaneous development of stationary reaction-diffusion patterns was predicted by the British mathematician Alan Turing ${ }^{1}$ more than 50 years ago. Such stationary concentration patterns typically develop in systems in which the competing activatory and inhibitory kinetic processes act on different space scales due to appropriate differences in the diffusion coefficients of species. In two variable kinetic systems, the onset of Turing patterns requires that the effective diffusion coefficient of the activator be sufficiently smaller than that of the inhibitory species, i.e., "short-range activation.",1,3,6 In more recent years, it has been shown that stationary patterns could also be generated by interactions between traveling fronts in bistable $^{14,15}$ and excitable ${ }^{16}$ systems. As in the previous case, the space scale separation of the kinetic processes plays a central role in the onset of those stationary patterns. Though not sufficient, the control of the relative mobility of species is a key factor in the quest for stabilized spatial patterns in a reacting solution. Two main approaches have been developed to selectively control the 
effective diffusivity of species: (i) The addition of uniformly distributed immobile (or reduced mobility) functional sites able to reversibly bind a targeted species. ${ }^{17,18}$ (ii) The use of finely dispersed multiphase systems where some species stay trapped in droplets of the minority phase, while others can diffuse in the continuum phase. ${ }^{19}$ Whether they result from a Turing instability or from front pairing interactions, up to now stationary patterns have been observed only in three different chemical systems: the chlorite-iodide-malonic acid (CIMA) reaction family, ${ }^{8}$ the ferrocyanide-iodate-sulfite (FIS) reaction, ${ }^{9,10}$ and in the Belousov-Zhabotinsky reaction dispersed in a water-in-oil reverse microemulsion. ${ }^{20}$ However, this multiphase technique seems to be restricted to those systems that can exhibit long-lived transient oscillatory behavior in a batch reactor, a kinetic property only fulfilled by less than a handful of reactions among the hundreds of well documented oscillating and bistable reactions. ${ }^{4,6}$ Based on the first approach for the control of the relative diffusion of species and on the systematic examination of front interactions in spatial bistable systems, we have proposed an orderly method to discover stationary patterns in chemically different systems. ${ }^{21}$ This led us to revisit the mechanisms at the origin of pattern formation in the FIS reaction, a chemical system prototypic of a large class of chemical oscillating reactions but which was left aside in recent experimental developments.

\section{INTRODUCTION}

The first clear experimental observation ${ }^{8}$ of Turing patterns was made by using the chlorite-iodide-malonic acid ${ }^{22}$ (CIMA) family of reactions. The chemical ${ }^{23}$ and physical mechanisms ${ }^{17,18}$ at play in the patterning processes of this system are well understood and controlled. ${ }^{17,24-26}$ Soon after the initial discovery, several teams could reproduce and expand the original observations. Many aspects of patterns were studied: one-,${ }^{24}$ two-,${ }^{25}$ and three-dimensional ${ }^{27-29}$ stationary periodic patterns, interaction between the Turing instability and the oscillatory Hopf instability, ${ }^{30}$ localized patterns, ${ }^{31}$ pattern growth dynamics, ${ }^{26}$ and the effect of temporary or permanent spatiotemporal forcing on the pattern mode selection and on the wavelength. ${ }^{32}$ In this system, it was theoretically proposed ${ }^{17}$ and experimentally demonstrated $^{24,26}$ that the required short-range activation is provided by complexing agents, such as starch or poly(vinyl)-alcohol, that reversibly bind the iodide ions, the activatory species. Much more recently, the BelousovZhabotinsky reaction dispersed in a water-in-oil reverse microemulsion was shown to also produce Turing and other types of patterns, including packet waves, dash waves, and segmented antispirals. ${ }^{20}$ Though quite complex, the transport and kinetic mechanisms at work in this system are reasonably well understood. However, this multiphase approach to the development of chemical patterns seems to be restrained to reactions that can exhibit long transient oscillatory dynamics in a batch reactor, a peculiar kinetic property very seldom observed in nonbiological systems and thus not exportable to the large majority of other documented oscillatory reactions. The majority of the chemical reactions that produce oscilla- tions work only in continuous (flow) stirred tank reactors (CSTR).

Soon after the discovery of Turing patterns in the CIMA systems, new types of stationary and dynamic patterns were discovered in the acid autoactivated ferrocyanide-iodatesulfite (FIS) reaction. ${ }^{9,10}$ The FIS reaction is a typical CSTR oscillator. The gross kinetic mechanism of this reaction is known. ${ }^{33-36}$ It can be described by two composite processes, where a hydrogen ion driven autocatalytic oxidation of hydrogen sulfite [(1) positive feedback] is coupled with a hydrogen ion consuming oxidation of ferrocyanide [(2) negative feedback],

$\mathrm{IO}_{3}^{-}+3 \mathrm{HSO}_{3}^{-} \rightarrow 3 \mathrm{SO}_{4}^{2-}+\mathrm{I}^{-}+3 \mathrm{H}^{+}$,

$\mathrm{IO}_{3}^{-}+6 \mathrm{H}^{+}+6\left[\mathrm{Fe}(\mathrm{CN})_{6}\right]^{4-} \rightarrow \mathrm{I}^{-}+6\left[\mathrm{Fe}(\mathrm{CN})_{6}\right]^{3-}+3 \mathrm{H}_{2} \mathrm{O}$.

Although, reaction (1) is autocatalytic both for protons and iodide ions, Rabai and co-workers assert that the kinetic role of the latter ones is negligible in unbuffered systems. ${ }^{36}$ The main activation is provided by the free protons.

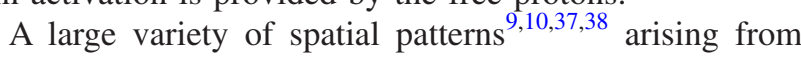
planar front multiplicity, front morphological instabilities, and front interactions were found in the FIS system. In particular, stationary labyrinthine patterns, self-replicating spots, and bouncing waves were observed when this reaction is operated in an open one-side-fed reactor (OSFR). Numerical studies based on a two- ${ }^{10}$ and later on a four-variable kinetic model revealed that most of the observed spatial patterns could be qualitatively accounted for by assuming that the diffusivity of hydrogen ions is less than that of the hydrosulfite ions, which conversely act as the main dynamic negative feedback species. ${ }^{37}$ However, there was no tested explanation as to how this assumption could be fulfilled. A priori, protons are the fastest diffusing ions in aqueous solutions. In a recent short report, ${ }^{39}$ we showed that in an agarose gel reactor, a number of original observations, in particular the development of stationary patterns, could not be reproduced if a supercritical amount of poly(acrylate), a charged polymer, was not introduced in the gel network. It is well established that due to the fast protonation equilibrium, weak acid functions with very low mobility can considerably decrease the effective diffusivity of protons. ${ }^{40,41}$ Though the presence of such low mobility acid functions was never considered, we argue that the same effect was provided by the hydrolysis of the poly(acrylamide) gel used in the original experiments but in an uncontrolled way. The more or less rapid degradation of amide functions to carboxylate functions, especially in alkaline aqueous solutions, is well known. ${ }^{42,43}$ In our approach, the low mobility carboxylate functions are provided by long acid polymer chains that impregnate the gel network, the concentration of which is controlled by the feed composition of the CSTR. This makes the complex pattern dynamics observed earlier easier to reproduce and their development more comprehensive. Here, we present a more detailed description of this renewed approach to the spatiotemporal patterns observed in this reaction and their dependence on different control parameters. 
(a)

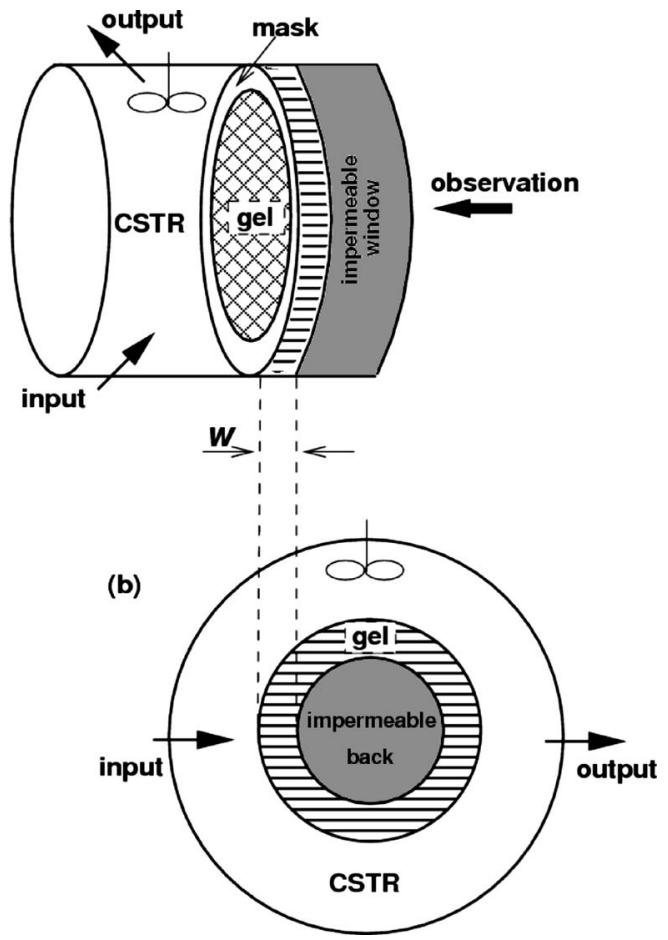

FIG. 1. Sketches of the reactors used in the experiments: disk-shaped OSFR (a) and annular OSFR (b), where $w$ is the thickness of the disk and width of the annulus.

\section{EXPERIMENTAL TECHNIQUES}

Two geometries of OSFR were used in the present experiments (Fig. 1): The first consists of a transparent thin disk ( $22 \mathrm{~mm}$ diam and $0.75 \mathrm{~mm}$ thick) made of $4 \%$ agarose gel (Fluka, BioChemika 05070). One face of the disk is in direct contact with the contents of a CSTR through a circular hole $(18 \mathrm{~mm}$ diam $)$ in a mask that holds the gel tightly immobilized against a flat observation window. Beyond the contact surface, the disk extends $(2 \mathrm{~mm}$ ) under the mask (for details, see Ref. 25). Patterns are observed by transparency and are monitored by a CCD video camera, connected to a video tape recorder and to a black and white frame grabber board. To enhance the contrast of the transmitted light patterns, a stabilized soft orange light illumination was shone opposite to the camera. The observations bring information on the integrated light absorption patterns across the thickness of the disk of gel but not on how these changes organize within the thickness. This complementary information is provided by a second OSFR geometry. It consists in a flat annular gel reactor ( $w=1 \mathrm{~mm}$ deep and $25 \mathrm{~mm}$ outer diameter) (for details, see Ref. 13). All the faces of the annulus are tightly pressed against impermeable walls except the outer edge, which is in direct contact with the contents of a CSTR. The observations, in reflected light, are made in a direction orthogonal to the feed surface and thus allow solving the color changes in the feed direction. This geometry of OFSR is self-sustained and offers periodic boundary conditions. It is free of boundary limit perturbations. In this respect, it mimics an infinite boundary system. However, in a series of experiments, an impermeable mask was glued over a small part of the outer rim of the annulus to mirror the edge effect that is present in the disk OSFR. Note that both reactors are confined in the direction of the feed, but while the disk reactor is extended in the two other directions (apparent twodimensional system), the annular reactor is extended only in one other direction (apparent one-dimensional system). All reported experiments were made at $30^{\circ} \mathrm{C}$ with a residence time of the CSTRs of $\tau=220 \mathrm{~s}$. The chemical solutions were stored in three separated reservoirs and injected by precision pumps (Pharmacia P500) with equal flow rates at the base of the CSTRs. They enter through a single port in the close vicinity of a turbine rotating at $1000 \mathrm{rpm}$. An overflow pipe maintains the reaction volume constant and at room pressure, with no air interface. The respective reservoirs contain the following: (1) potassium iodate (Fluka); (2) sodium sulfite (Fluka), potassium ferrocyanide (Acros Organics), and sodium poly(acrylate) (Aldrich, MW:15 000 Dalton); (3) sulfuric acid (Roth). In the disk OSFR experiments, bromothymol blue (Acros Organics), a $p \mathrm{H}$ color indicator that switches from blue to yellow in the 7.6-6.2 $\mathrm{pH}$ range, was added $(0.3 \mathrm{~g} / \mathrm{L})$ in reservoirs 1 and 2 , while bromocresol green was used at the same weight concentration in the annular OSFR experiments. This $p \mathrm{H}$ indicator switches from blue to light yellow in the 5.4-3.8 $p \mathrm{H}$ range. All the chemicals are analytical grade and solutions are prepared in deionized water. The feed concentration of potassium iodate $\left[\mathrm{KIO}_{3}\right]_{0}$ and sodium sulfite $\left[\mathrm{Na}_{2} \mathrm{SO}_{3}\right]_{0}$ was fixed at 75 and $89 \mathrm{mM}$, respectively. Here []$_{0}$ denotes the concentration that the input species would have after mixing and prior to any reaction. To explore the dynamics of the system, we varied the feed concentration of ferrocyanide $\left[\mathrm{K}_{4} \mathrm{Fe}(\mathrm{CN})_{6}\right]_{0}$, sulfuric acid $\left[\mathrm{H}_{2} \mathrm{SO}_{4}\right]_{0}$, and poly(acrylate) $[\mathrm{PA}]_{0}$ in the ranges $0-20,0-4.17$, and $0-4 \mathrm{mM}$, respectively. The value of $[\mathrm{PA}]_{0}$ corresponds to the concentration of carboxylic groups in the feed solution introduced by the poly(acrylate) polymer chains. These polyacid chains slowly diffuse in the agarose gel where their asymptotic concentration is expected to be close to that of the CSTR solution. For each new PA feed concentration, the gel parts of the reactors were left to impregnate in a solution with the targeted value, for at least $24 \mathrm{~h}$.

\section{EXPERIMENTAL RESULTS}

Let us first describe the CSTR dynamics. In the range of chemical feed parameter used in this paper, the CSTR content exhibits bistability between a high $p \mathrm{H}(8-6)$ and a low $p \mathrm{H}$ (3.5-4.0) steady-state branch. They correspond, respectively, to the so-called "flow" and "thermodynamic" branches. ${ }^{33}$ On the flow branch, the extent of the reaction is small and the concentration of the input species generally does not differ much from the composition in the input flow, while on the thermodynamic branch the extent of the reaction is large. The switch from one branch to the other depends sensitively on the sulfuric acid feed concentration $\left(\left[\mathrm{H}_{2} \mathrm{SO}_{4}\right]_{0}\right)$, which is conveniently used as the tunable control parameter throughout the experiments. Introducing ferrocyanide, the antagonist feedback species, decreases the range of steady-state bistability in the CSTR. Above a critical ferrocyanide feed concentration, the CSTR content may 


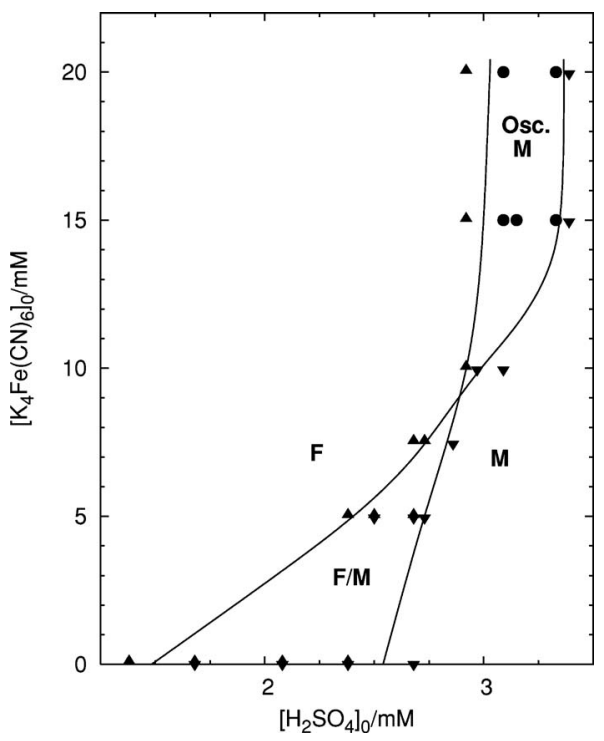

FIG. 2. Experimental nonequilibrium phase diagram in the $\left(\left[\mathrm{K}_{4} \mathrm{Fe}(\mathrm{CN})_{6}\right]_{0}\right.$, $\left[\mathrm{H}_{2} \mathrm{SO}_{4}\right]_{0}$ ) plane. Symbols attributed to states of the gel: $\boldsymbol{\nabla}$ stable $\mathrm{M}$ state; $\boldsymbol{\Delta}$ stable F state; oscillatory M state. The lines indicate the limit of the spatial states.

exhibit large-amplitude $p \mathrm{H}$ oscillations, as shown in Ref. 33. In this paper, the content of the CSTR was always maintained on the stationary state branch with the lowest extent of reaction, i.e., the high $p \mathrm{H}$ flow branch.

\section{Spatial bistability, oscillations, and front interaction in an annular OSFR}

In Fig. 2, we present a section of phase diagram in the $\left(\left[\mathrm{K}_{4} \mathrm{Fe}(\mathrm{CN})_{6}\right]_{0},\left[\mathrm{H}_{2} \mathrm{SO}_{4}\right]_{0}\right)$ plane for the annular OSFR. The phase diagram was established by gradually changing $\left[\mathrm{H}_{2} \mathrm{SO}_{4}\right]_{0}$ for different fixed values of the $\left[\mathrm{K}_{4} \mathrm{Fe}(\mathrm{CN})_{6}\right]_{0}$. Different spatial states can be observed in the gel depending on $\left[\mathrm{H}_{2} \mathrm{SO}_{4}\right]_{0}$ and on the initial state of the gel contents. In the absence of ferrocyanide at $\left[\mathrm{H}_{2} \mathrm{SO}_{4}\right]_{0}=0 \mathrm{mM}$, the gel is in a quasiuniform dark color state [Fig. 3(A)], the F-state of the OSFR. In the pictures, the dark and light gray colors correspond, respectively, to high and low $p \mathrm{H}$ compositions in gel. The F-state of the gel is stable up to $\left[\mathrm{H}_{2} \mathrm{SO}_{4}\right]_{0}=2.38 \mathrm{mM}$. A further increase of $\left[\mathrm{H}_{2} \mathrm{SO}_{4}\right]_{0}$ to $2.68 \mathrm{mM}$ makes the innermost part of the annulus suddenly turn clear. A stable $p \mathrm{H}$ indicator color switch settles parallel to the rim of the annulus, as illustrated in Fig. 3(B); this is the mixed state $\mathrm{M}$ of the OSFR. Now, decreasing $\left[\mathrm{H}_{2} \mathrm{SO}_{4}\right]_{0}$, the M-state remains stable down to $1.68 \mathrm{mM}$. Lowering $\left[\mathrm{H}_{2} \mathrm{SO}_{4}\right]_{0}$ to $1.04 \mathrm{mM}$

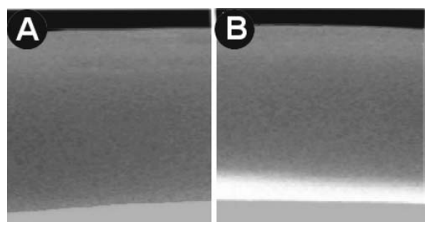

FIG. 3. Stationary F (A) and M (B) states observed in the annular OSFR. The upper part of the gel strip is in contact with the CSTR contents (black), the bottom is an impermeable wall (light gray). In between the gray scale changes from medium gray to white correspond to the $p \mathrm{H}$ color indicator chances in the gel, from the alkaline to the acid form.
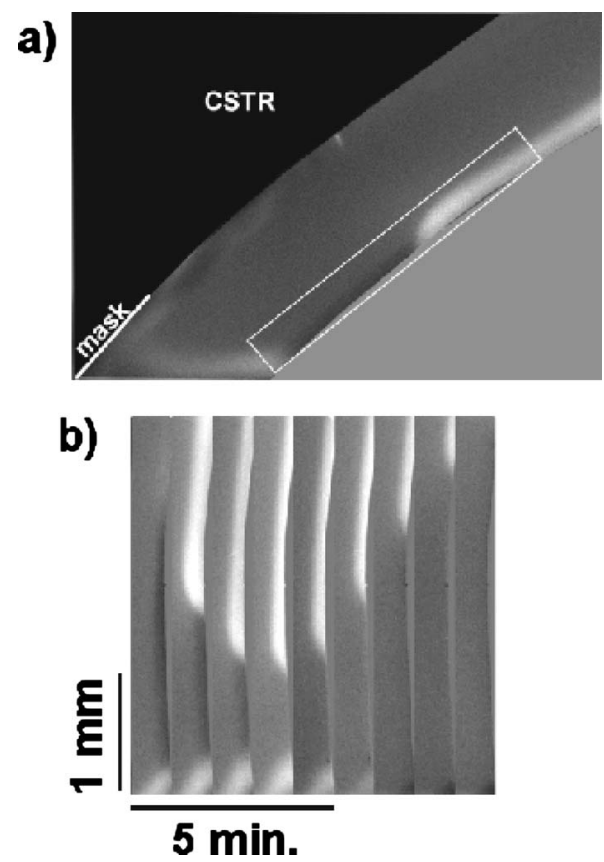

FIG. 4. Front interaction and oscillations observed in the annular OSFR at $\left[\mathrm{H}_{2} \mathrm{SO}_{4}\right]_{0}=3.09 \mathrm{mM}$ and $\left[\mathrm{K}_{4} \mathrm{Fe}(\mathrm{CN})_{6}\right]_{0}=20 \mathrm{mM}$. The left part of the annular gel is masked, no direct contact with the CSTR. The location of the mask is indicated by a white stripe (a). The white rectangle indicates the area used in the spatio-temporal representation (b), where the sampling time is $1 \mathrm{~min}$.

makes the contents of the annulus return to the uniformly dark F-state. The stability range of the $\mathrm{F}$ and the $\mathrm{M}$ states of the gel overlaps between $\left[\mathrm{H}_{2} \mathrm{SO}_{4}\right]_{0}=1.68$ and $2.38 \mathrm{mM}$; this is spatial bistability. ${ }^{44}$ In the range of spatial bistability, an appropriate perturbation can create interfaces between the $\mathrm{M}$ and the $\mathrm{F}$ states. The direction of the propagation of the interface depends on the actual value of $\left[\mathrm{H}_{2} \mathrm{SO}_{4}\right]_{0}$. Clear differences can be observed between the acid producing (+)front (transition from F- to M-state) and the acid consuming (-)front (transition from M- to F-state). A (+)front exhibits a small overshoot of the radial extension of the acid core while the acidic part is narrower in the vicinity of a (-)front (Fig. 4).

The extent of the domain of spatial bistability decreases as $\left[\mathrm{K}_{4} \mathrm{Fe}(\mathrm{CN})_{6}\right]_{0}$ is increased and vanishes at a critical value $\left(\left[\mathrm{K}_{4} \mathrm{Fe}(\mathrm{CN})_{6}\right]_{0}=10 \mathrm{mM}\right)$. Let us describe the changes of states above this limit, e.g., at $\left[\mathrm{K}_{4} \mathrm{Fe}(\mathrm{CN})_{6}\right]_{0}=15 \mathrm{mM}$. Starting from $\left[\mathrm{H}_{2} \mathrm{SO}_{4}\right]_{0}=0$, the content of the gel is in the F-state until $\left[\mathrm{H}_{2} \mathrm{SO}_{4}\right]_{0}=2.92 \mathrm{mM}$. A further increase to $\left[\mathrm{H}_{2} \mathrm{SO}_{4}\right]_{0}$ $=3.09 \mathrm{mM}$ makes the innermost part of the gel suddenly become acidic. As above, a mixed state appears but now the switching position of the color indicator is no longer stable but moves back and forth across the width $w$ of the annulus, in a way somewhat similar to what was observed with the iodate-sulfite reaction. ${ }^{13}$ The domain of existence of this oscillatory state interchanges with the domain of spatial bistability through a typical cross-shaped phase diagram topology ${ }^{45}$ (Fig. 2).

We show later that in this system, pattern developments are mainly governed by front interactions. One special feature of the front dynamics in the disk OSFR is the "bouncing" of (+)fronts as they approach the rim of the circular 


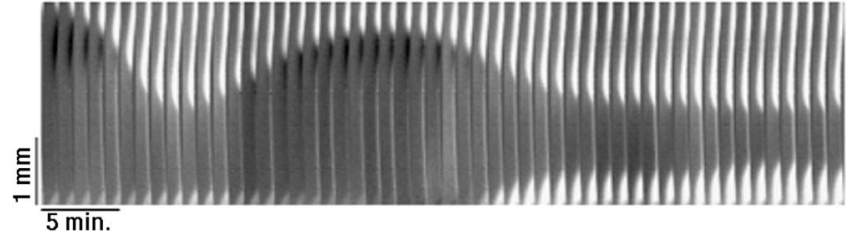

FIG. 5. Formation of a stable pulse in the presence of poly(acrylate) $\left([\mathrm{PA}]_{0}=4 \mathrm{mM}\right)$ at $\left[\mathrm{H}_{2} \mathrm{SO}_{4}\right]_{0}=3.33 \mathrm{mM}$ and $\left[\mathrm{K}_{4} \mathrm{Fe}(\mathrm{CN})_{6}\right]_{0}=20 \mathrm{mM}$. The spatio-temporal representation shows the same part of the gel as in Fig. 4.

mask. To understand this bouncing phenomenon, we have glued a mask over a small part of the annular OSFR. In the parts of the gel under the mask, the extent of the reaction is naturally greater than in the parts directly in contact with the contents of the CSTR. The composition under the mask turns acidic before the rest of the gel. However, as illustrated in Fig. 4, the M-state does not propagate from under the mask but develops at a distance. The observations are summarized in Fig. 4. A (+)front approaches the mask, slows down, stops, and then reverses direction. At the same time, the acid part under the mask extends slightly and then recedes. The propagation of the (+)front $(\sim 1.6 \mathrm{~mm} / \mathrm{min})$ is faster than that of the (-)front $(\sim 0.5 \mathrm{~mm} / \mathrm{min})$.

Introducing PA, as a low mobility proton binding agent, changes significantly the dynamics of the system. Figure 5 shows the interaction of a front with the composition under the masked area of the annular reactor, when $[\mathrm{PA}]_{0}=4 \mathrm{mM}$. Starting with the annular reactor uniformly in the F-state at $\left[\mathrm{H}_{2} \mathrm{SO}_{4}\right]_{0}=2.92 \mathrm{mM}$, an increase to $\left[\mathrm{H}_{2} \mathrm{SO}_{4}\right]_{0}=3.33 \mathrm{mM}$ leads to the formation of a (+)front, which approaches the masked area and bounces, in a somewhat similar way to that shown in Fig. 4. However, the initial rate of approach and withdrawal of the (+)front and (-)front are a factor 3 slower than in the absence of PA. Then, the F/M-state interface reverses once more and approaches again the masked area, whereas at the same time the acidic zone under the mask outstretches again. The F/M-state interface finally stops at a finite distance from the edge of the mask. A stable F-state pulse $(\sim 0.9 \mathrm{~mm}$ wide) forms in between two M-state regions (Fig. 5). These observations show that by introducing PA, a nontrivial stationary structure may develop spontaneously. Under these feed conditions, we did not observe the formation of other pulses far from the edge of the mask.

\section{Fronts and labyrinthine patterns in a disk OSFR}

The disk OSFR is characterized by a higher dimensionality where the curvature of fronts in the plane parallel to the feed can play an important role in the dynamics of the system.

Let us start again with observations made in the absence of PA. Consistently with the phase diagram in Fig. 2, the dynamic and patterning capacities of the system depend critically on the $\left[\mathrm{K}_{4} \mathrm{Fe}(\mathrm{CN})_{6}\right]_{0}$ value. For $\left[\mathrm{K}_{4} \mathrm{Fe}(\mathrm{CN})_{6}\right]_{0} \leq 10 \mathrm{mM}$, only the uniform steady states $\mathrm{F}$ or $\mathrm{M}$ are asymptotically observed as a function of $\left[\mathrm{H}_{2} \mathrm{SO}_{4}\right]_{0}$, whereas for $\left[\mathrm{K}_{4} \mathrm{Fe}(\mathrm{CN})_{6}\right]_{0}=20 \mathrm{mM}$, a value leading to M-state oscillations in Fig. 2, more or less complex traveling

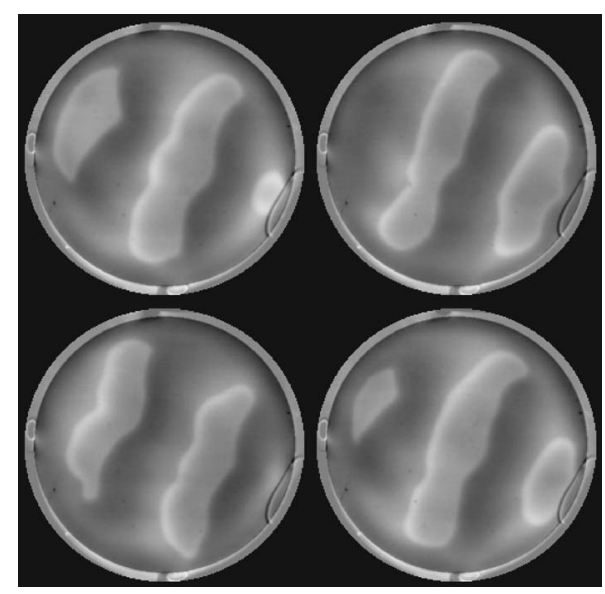

FIG. 6. Traveling M-state domains in the disk OSFR at $\left[\mathrm{H}_{2} \mathrm{SO}_{4}\right]_{0}$ $=2.86 \mathrm{mM} ;\left[\mathrm{K}_{4} \mathrm{Fe}(\mathrm{CN})_{6}\right]_{0}=20 \mathrm{mM} ;[\mathrm{PA}]_{0}=0$. Sampling time of snapshots $6 \mathrm{~min}$.

domain patterns delimited by (+)fronts and acid (-)fronts, can be observed. In Fig. 6, the (+) and (-)fronts are distinguished, respectively, by a sharp change to a bright M-state braid and to a darker F-state zone. While distinctive colors can be seen with the naked eye in the state of the disk (blue for the F-state and brownish blue for the M-state), these two states cannot always be discriminated by their gray level but their interfaces always exhibit a sharp switch in the gray level, as explained above. Starting with the gel reactor uniformly in the F-state at $\left[\mathrm{H}_{2} \mathrm{SO}_{4}\right]_{0}=2.80 \mathrm{mM}$, a supercritical increase of $\left[\mathrm{H}_{2} \mathrm{SO}_{4}\right]_{0}$ to $2.92 \mathrm{mM}$ leads to the spontaneous growth of an M-state domain at pacemaker regions close to the rim of the mask but never in direct contact with the contents of the gel under the mask, as was the case in the annular OSFR experiments. The M-state domain starts to expand in all directions, but this expansion stops at a finite distance from the mask. The sign of the front reverses, and leads to a recovery of the F-state. After some time, a new patch of M-state grows. As a result, except for a narrow ring area $(\sim 1.3 \mathrm{~mm}$ wide) in the vicinity of the mask, every space point of the disk undergoes large-amplitude $p \mathrm{H}$ oscillations with a period of about $16 \mathrm{~min}$. This behavior can be related to the periodic "shrinking ring" phenomenon reported in the original publications. ${ }^{38}$ However, in our case the domain oscillations become more complex due to different possible front interactions. Fronts of the same sign annihilate on head-on collision. A head-to-back interaction between fronts of opposite sign can cause the (+)front to change sign, while the connection of fronts of opposite sign along the same M-state domain usually leads to the development of domain states rotating around this singularity, i.e., spiraling domain growths (Fig. 7). When the connection occurs in the close vicinity of the M-state excluded area next to the rim of the mask, the rotation is impeded and the singularity drifts along the above quiescent area. Remarkably, at high enough $\left[\mathrm{H}_{2} \mathrm{SO}_{4}\right]_{0}$ and still in the absence of PA, a repulsion develops between (-)fronts and leads to the formation of more or less long-lived "filaments" of the M-state which eventually swell again as the (-)fronts revert to (+)fronts. This is seen when $\left[\mathrm{H}_{2} \mathrm{SO}_{4}\right]_{0}$ is increased to $3.09 \mathrm{mM}$ in the two lower snap- 


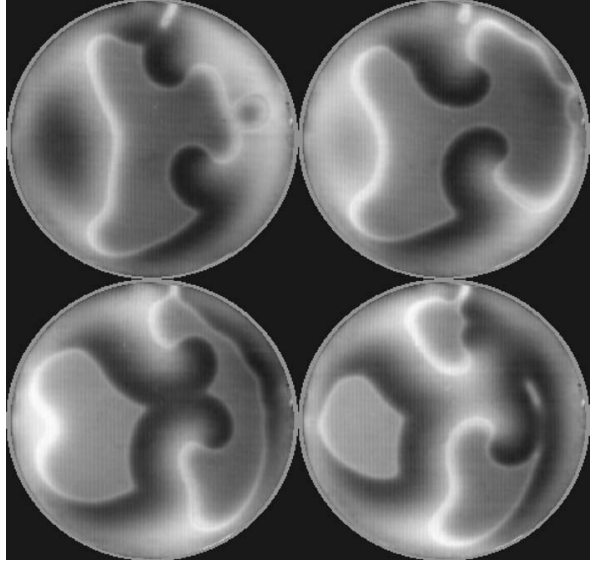

FIG. 7. Spiraling M-state domains in the disk OSFR at $\left[\mathrm{H}_{2} \mathrm{SO}_{4}\right]_{0}$ $=2.92 \mathrm{mM} ;\left[\mathrm{K}_{4} \mathrm{Fe}(\mathrm{CN})_{6}\right]_{0}=20 \mathrm{mM} ;[\mathrm{PA}]_{0}=0$. Sampling time of snapshots from top left to right and down $4 \mathrm{~min}$.

shots in Fig. 8. Another general observation, in the domain of parameter explored, is the fact that contrary to the M-state, which can spontaneously emerge inside an F-state domain, F-state "bubbles" never spontaneously form in the middle of an M-state region. Patchy F-state patterns such as that in Fig. 8 are the result of F-state trapping between growing domains of M-state, as seen in the first two snapshots in Fig. 8. In this trapping mechanism, an F-state bubble survives only if surrounded by a (-)front and if it is large enough.

Let us continue the description of pattern development at $\left[\mathrm{K}_{4} \mathrm{Fe}(\mathrm{CN})_{6}\right]_{0}=20 \mathrm{mM}$, a feed value at which oscillations are observed in the absence of PA. When $[\mathrm{PA}]_{0}$ is increased to $0.5 \mathrm{mM}$, dynamical patterns similar to those described above are observed. However, when $[\mathrm{PA}]_{0}=1 \mathrm{mM}$, stationary lamellar patterns can be observed in addition (see Fig. 2E in Ref. 39). This is exemplified in Fig. 9, which shows the formation of a stable M-state network pattern at $[\mathrm{PA}]_{0}$ $=2 \mathrm{mM}$ : After changing $\left[\mathrm{H}_{2} \mathrm{SO}_{4}\right]_{0}$ from $2.67 \mathrm{mM}$, a value for which the disk is in the uniform F-state, to $\left[\mathrm{H}_{2} \mathrm{SO}_{4}\right]_{0}$ $=2.98 \mathrm{mM}$, a stationary pattern develops with the initial spontaneous appearance of an M-state domain, which grows,

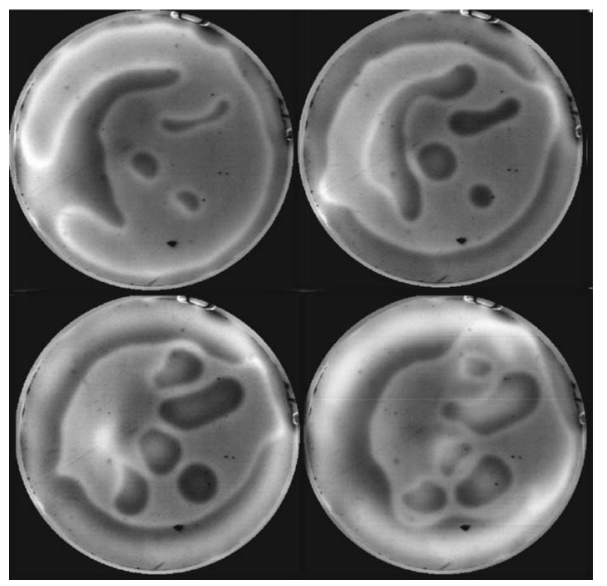

FIG. 8. Large oscillatory M-state domain with trapping growth and death of small F-state domains and formation of long-lived M-state filaments at $\left[\mathrm{H}_{2} \mathrm{SO}_{4}\right]_{0}=3.09 \mathrm{mM} ;\left[\mathrm{K}_{4} \mathrm{Fe}(\mathrm{CN})_{6}\right]_{0}=20 \mathrm{mM} ;[\mathrm{PA}]_{0}=0$. Sampling time of snapshots $4 \mathrm{~min}$.

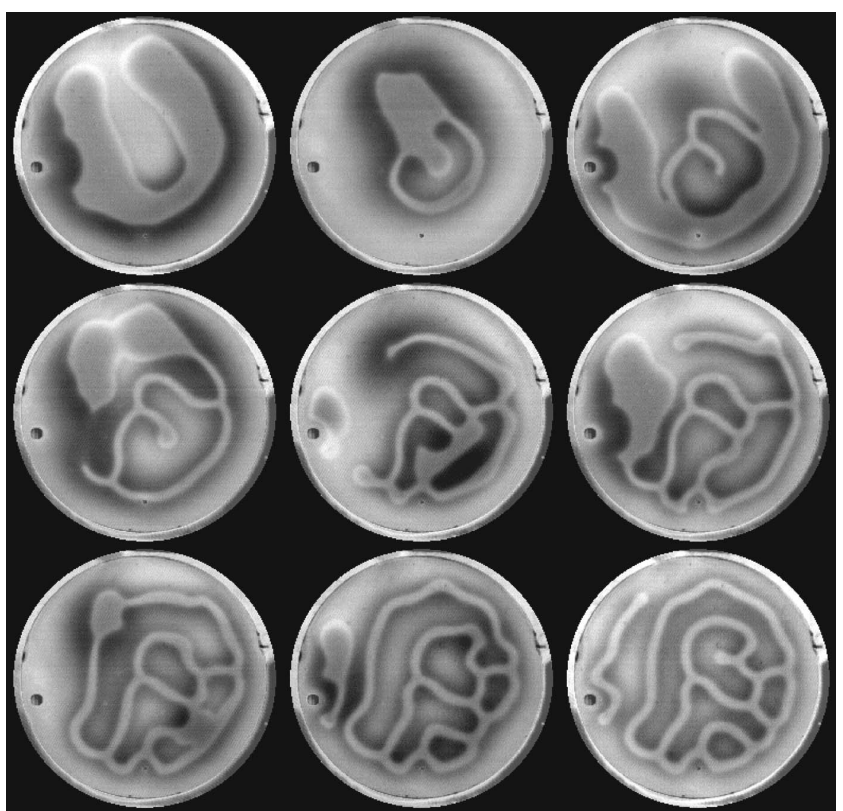

FIG. 9. Development of a stable labyrinthine pattern at $\left[\mathrm{H}_{2} \mathrm{SO}_{4}\right]_{0}$ $=2.98 \mathrm{mM} ;\left[\mathrm{K}_{4} \mathrm{Fe}(\mathrm{CN})_{6}\right]_{0}=20 \mathrm{mM} ;[\mathrm{PA}]_{0}=2.0 \mathrm{mM}$. Sampling time of snapshots from left to right and down 10 min except between the two last ones $30 \mathrm{~min}$

bounces at the rim, and starts to form persistent M-state filaments. Once they are formed, these filaments contribute to their further invasion by different oscillatory strategies. A free tip may shrink and swell while other parts of the filaments develop a breathing dynamics that makes them move and bud when no other front is at a close critical distance. This mechanism is continuous until the mutual "repulsive" interaction between the filaments freezes the space-filling dynamic. A stationary lamellae pattern with a relatively narrow wavelength distribution settles $2 \mathrm{~h}$ after the supercritical feed change.

Starting with the above stationary pattern, if $\left[\mathrm{H}_{2} \mathrm{SO}_{4}\right]_{0}$ is increased further to $3.09 \mathrm{mM}$, the relative stability of the $\mathrm{M}$-state increases at the expense of the F-state and the M-state becomes the majority state, as shown in Fig. 10.

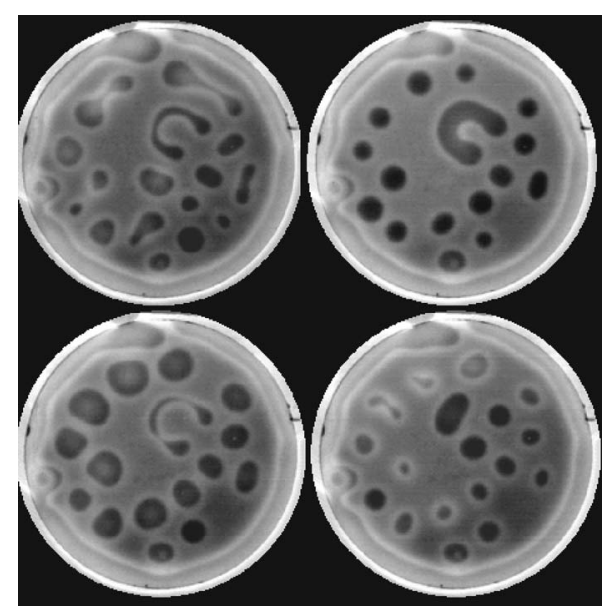

FIG. 10. Dynamics of F-state bubbles trapped in a large M-state domain at $\left[\mathrm{H}_{2} \mathrm{SO}_{4}\right]_{0}=3.09 \mathrm{mM} ; \quad\left[\mathrm{K}_{4} \mathrm{Fe}(\mathrm{CN})_{6}\right]_{0}=20 \mathrm{mM} ; \quad[\mathrm{PA}]_{0}=2.0 \mathrm{mM}$. Sampling time of snapshots from left to right and down $8 \mathrm{~min}$. 


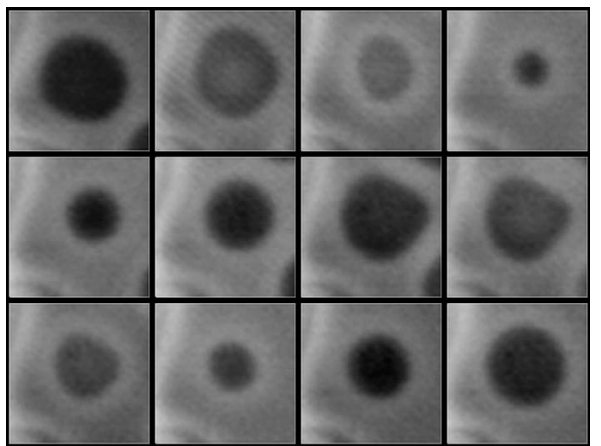

FIG. 11. Breathing small F-state domain. Period of oscillations 24 min. Conditions as in Fig. 10. Sampling time of snapshots from left to right and down $4 \mathrm{~min}$. Size of the frames $3.5 \times 3.5 \mathrm{~mm}$.

After this $\left[\mathrm{H}_{2} \mathrm{SO}_{4}\right]_{0}$ jump, many F-state bubbles are trapped and the dynamic of the pattern is then ruled by that of the F-state bubbles. These may divide, pulsate, and eventually die by overgrowth with the spontaneous development of the $\mathrm{M}$-state in their middle or a local asymmetric commutation of a (-)front to a (+)front, which deforms the circular symmetry of the bubble. The system no longer settles into a stationary pattern mode. Note that the spot pattern is inserted in a large discoid $\mathrm{M}$-state domain disconnected from the mask (except at one point, at 12 o'clock in the snapshotsFig. 10, probably due to some local "boundary imperfection"). The diameter of this discoid M-state domain undergoes small-amplitude oscillations with a period of about 24 min, similar to that of the oscillatory F-state spots. The sequence of snapshots in Fig. 11 details the breathing dynamics of a small F-state spot of Fig. 10. Note the color changes inside the spot when it grows or shrinks, indicating that the $p \mathrm{H}$ decreases when the spot shrinks and vice versa.

We have also explored the effect of ferrocyanide feed concentration on pattern formation in the disk OSFR. For simplicity reasons, let us only consider the case of stationary patterns at $[\mathrm{PA}]_{0}=4 \mathrm{mM}$ and $\left[\mathrm{H}_{2} \mathrm{SO}_{4}\right]_{0}=2.86 \mathrm{mM}$. In these conditions, the gel is in the stationary $\mathrm{F}$-state when $\left[\mathrm{K}_{4} \mathrm{Fe}(\mathrm{CN})_{6}\right]_{0}<5 \mathrm{mM}$. At $\left[\mathrm{K}_{4} \mathrm{Fe}(\mathrm{CN})_{6}\right]_{0}=5 \mathrm{mM}$, the gel switches to the stationary uniform M-state; no nontrivial patterns are observed. Above a critical $\left[\mathrm{K}_{4} \mathrm{Fe}(\mathrm{CN})_{6}\right]_{0}$ around $10 \mathrm{mM}$, the $\mathrm{M}$-state become unstable and a stationary M-state labyrinthine pattern forms, as illustrated in Fig. 12(a) for $\left[\mathrm{K}_{4} \mathrm{Fe}(\mathrm{CN})_{6}\right]_{0}=15 \mathrm{mM}$. The area covered by the $\mathrm{M}$-state and the interconnections in the network increase with increasing $\left[\mathrm{K}_{4} \mathrm{Fe}(\mathrm{CN})_{6}\right]_{0} \quad[$ Fig. $12(\mathrm{~b})]$. At

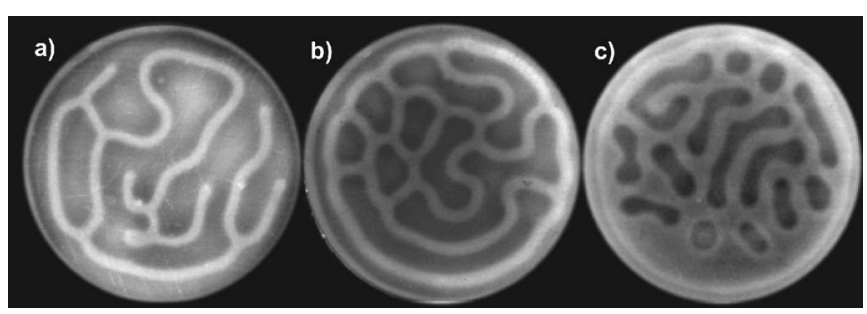

FIG. 12. Pattern observed at different $\left[\mathrm{K}_{4} \mathrm{Fe}(\mathrm{CN})_{6}\right]_{0}$. Experimental conditions: $\left[\mathrm{H}_{2} \mathrm{SO}_{4}\right]_{0}=2.86 ; \quad[\mathrm{PA}]_{0}=4 \mathrm{mM}, \quad\left[\mathrm{K}_{4} \mathrm{Fe}(\mathrm{CN})_{6}\right]_{0}=15$ (a), 25 (b), $30 \mathrm{mM}(\mathrm{c})$.
$\left[\mathrm{K}_{4} \mathrm{Fe}(\mathrm{CN})_{6}\right]_{0}=30 \mathrm{mM}$, similarly to observations made at high $\left[\mathrm{H}_{2} \mathrm{SO}_{4}\right]_{0}$ (Fig. 9), the stationary network pattern loses stability and the system is dominated by the birth and death dynamics of F-state spots [Fig. 12(c)].

Test experiments were also made as a function of temperature. At $[\mathrm{PA}]_{0}=2 \mathrm{mM}$ and $\left[\mathrm{K}_{4} \mathrm{Fe}(\mathrm{CN})_{6}\right]_{0}=20 \mathrm{mM}$, stationary lamellae patterns could be observed at 22 and $33{ }^{\circ} \mathrm{C}$ by adjusting the value of $\left[\mathrm{H}_{2} \mathrm{SO}_{4}\right]_{0}$. The pattern parameter domain shifts to higher acid feed with decreasing temperature. Noteworthy, at $22{ }^{\circ} \mathrm{C}$, no CSTR oscillation is observed but only bistability. ${ }^{33,34}$

\section{DISCUSSION}

In this paper, we revisit the conditions for the observations of reaction-diffusion patterns when operating the ferrocyanide-iodate-sulfite reaction in a one-side-fed spatial reactor. Despite the fantastic patterning capacity of this system (due to morphological front instabilities and an IsingBloch front bifurcation), it was left dormant for about 15 years, contrary to the case of the CIMA reaction. Due to some unnoticed and thus uncontrolled charge contents of the gels, the original experimental observations were difficult to reproduce. Lets us point out the similarities and differences between the original and our present experimental method. Both sets of experiments were made in the same range of chemical feed parameters and temperature. The CSTR residence time in the original experiments ranged from 36 to $240 \mathrm{~s}$, which is shorter by a factor 6 or equivalent to ours. Conversely, the volume of our stirred tank reactor is significantly greater to minimize feedback effects of the contents of the gel on the actual composition of the CSTR-i.e., to minimize global coupling effects. In this type of reactor, global coupling cannot be totally avoided but in the present experiments it does not drive the overall pattern dynamics. ${ }^{46}$ The main differences come from the polymer gels used in the two sets of experiences and the way they are set in contact with the CSTR contents. The original experiments used $16 \%$ weight polyacrylamide gels films $(0.2-0.6 \mathrm{~mm}$ thick $)$ in contact with the CSTR contents through an aluminum oxide and a nitrocellulose membrane to provide, respectively, structural rigidity and a white backing for visualization. We use no such composite of porous membrane with unknown chemical adsorption properties. In our experiments, a single porous material is used-agarose ( $4 \%$ weight) — a better characterized gel that should make experimental reproducibility easier. Our gels are thicker $(w=0.75 \mathrm{~mm}$ for the disk geometry OSFR and $1.0 \mathrm{~mm}$ in the annular one). Pattern development can be very sensitive to the thickness $w$ as shown in the original set of publications ${ }^{38}$ and in recent studies with other bistable systems. ${ }^{47-49} \mathrm{Li}$ et al. ${ }^{38}$ report observation of no patterns for gels thicker than $0.4 \mathrm{~mm}$, which is not our case. However, because the acrylamide and agarose gels have very different structures and because of the presence of additional membranes in the original experiments, it is difficult to compare the effective thickness-i.e., characteristic exchange time between the feed surface and the opposite face of the gel reactors-in the old and new sets of experiments. Further 
studies on size effect would be required to understand some of the differences between the two sets of experiments.

There are different theoretical approaches in the literature to describe the formation of labyrinthine patterns and spot division, ${ }^{14,50}$ but the presence of a long-range inhibition and correlatively a short-range activation is always considered to be an important condition. We argue that in original experiments, as in the ones introduced here, an effective sufficiently short activation range was mediated by supercritical concentrations of low mobility "weak" acid functions. Here, the low mobility protonable functions are mostly provided by poly(acrylate) chains directly fed at controlled concentration in the CSTR, while in the original experiments they were provided by the uncontrolled hydrolysis of the polyacrylamide gel itself. It is known that the amide functions can be readily hydrolyzed into carboxylate functions in alkaline solution. ${ }^{42,43}$ This hydrolysis is favored by the increase of alkalinity of the solutions but also by the presence of different ions. In standard polyacrylamide gels, the amide units are in molar concentration and only a few tenths of a percent need to be hydrolyzed to generate supercritical amounts of carboxylate functions. It was also reported ${ }^{9}$ that similar patterns could be observed using agar gels but that these gels would rapidly degrade. Agar gels are heavily charged gels; they are a mixture of about $70 \%$ agarose (uncharged polysaccharide) and 30\% agaropectin (charged sulfated polysaccharides including D-glucuronic and pyruvic acids). The effective diffusivity of protons would naturally be quite low in such gels. Our agarose gels do not degrade over periods of time of the order of the week and are only very slightly charged. ${ }^{50} \mathrm{We}$ think that it is not necessary to invoke more complex indirect mechanisms such as the immobilization of other active species such as iodine. ${ }^{52}$ However, this qualitatively seductive hypothesis was not experimentally tested and would not account for previous observations in gels as different as polyacrylamide and agar.

We observe most of the qualitative behaviors reported in the original publications. While in the original publications stationary patterns are found in both the spatial bistability parameter region ${ }^{37}$ and in the oscillatory region, ${ }^{38}$ here we have observed such patterns only in the oscillatory region of the parameter. Our patterns develop for $\left[\mathrm{K}_{4} \mathrm{Fe}(\mathrm{CN})_{6}\right]_{0}>10 \mathrm{mM}$. At this value, spatial bistability has vanished and no external perturbation is needed to trigger an interfaces between the F- and $\mathrm{M}$-states. We have made no spatial light or feed perturbation by, i.e., stopping the stirring of the CSTR as in Ref. 38. The patterns develop spontaneously beyond a critical $\left[\mathrm{H}_{2} \mathrm{SO}_{4}\right]_{0}$ value through the periodic growth of M-state domains at random pacemaker positions. Note that boundaries and pacemakers that break the uniformity of the system can be thought of as permanent extrinsic perturbations of the system. We should also mention that within our experimental acid feed steps of $0.06 \mathrm{mM}$, we observed no hysteresis in the onset of stationary or traveling patterns.

In the absence of poly(acrylate), special attention should be paid to the observation of long-lived M-state filaments at high $\left[\mathrm{H}_{2} \mathrm{SO}_{4}\right]_{0}$. These transient filamentous structures result from the flattening of colliding (-)fronts associated with the growth of circular domains of F-states. This sort of "repulsive" interaction could suggest that a long-range inhibitory and short-range activatory mechanism is already at play, inferring that the proton is already significantly slowed down. Let us examine this possibility. Besides the oxygenated iodine and the iron cyanide compounds which have diffusion coefficients of the same order of magnitude as that of the hydrosulfite ions, and thus would not make the associated protons diffuse slower than this ion, there are two possibilities: the $p \mathrm{H}$ color indicators that have a molecular mass around $700 \mathrm{D}$ or the residual impurities in the agarose gel. ${ }^{51}$ To provide suitable color contrasts for the detection of patterns, relatively high concentrations $(\sim 0.3 \mathrm{mM})$ of $p \mathrm{H}$ color indicators were used, concentrations that are in the same range of magnitude as those of protons in the acid part of the M-state. However, recently the same (-)front flattening was observed in the absence of a $p \mathrm{H}$ indicator, using polyvinylalcohol, which acts as a polyiodide ion color indicator, ${ }^{53}$ a species that forms in the fronts. In this vein, we are left with the possible contributions of the residual charges in the agarose gels. These residual gel charges are likely provided by agaropectin compounds such as D-glucuronic and pyruvic acids, which have a $p K_{a}$, respectively, of 2.9 and 2.4.

Another possibility is that on increasing $\left[\mathrm{H}_{2} \mathrm{SO}_{4}\right]_{0}$, the system comes very close to the nonequilibrium Ising-Bloch front bifurcation limit. In this critical parameter region, the front flattening mechanism would not necessarily require short-range activation. It is now well established ${ }^{14}$ that in the vicinity of a nonequilibrium Ising-Bloch front bifurcation, the velocity of the fronts becomes very sensitive to intrinsic parameters such as curvature or front pair interactions. In this case, the velocity and direction of propagation of two fronts could depend critically on their distance. This latter front interaction mechanism would be supported by the observation that after some time, the filamentous structures swell again. A clear discrimination between the two possible mechanisms is probably not an easy experimental task since the two mechanisms can combine. In all cases, experiments with purer agarose gels would be necessary.

Finally, we would like to emphasize that this revival of observation of labyrinthine patterns and other involved spot dynamics in the FIS reaction, in a quite different gel-filled open spatial reactor, stems from the systematic design method that we have recently proposed to discover standing reaction-diffusion patterns in chemically different reactions. ${ }^{21}$ The method is based on the finding of the spatial bistability phenomenon in OSFRs and the study of front interactions in these and neighboring regions of parameter space, and then selectively reducing the effective diffusivity of the main activator species by introducing controlled amounts of low mobility complexing agents. Our method was first successfully applied to the chlorine-dioxide-iodidemalonic acid (CDIIMA) reaction, ${ }^{21}$ a spatially bistable reaction that is an extended version of the reaction that first produced ${ }^{8}$ Turing patterns. Though the patterns observed in the CDIIMA system are not as rich as those observed in the FIS reaction, we find strong similar requirements for the development of stationary patterns. In particular, besides a critical concentration of an appropriate complexing agent, it 
is necessary also to introduce a critical concentration of an independent species that could act as a source or sink of the activator and the diffusivity of which is not reduced by the low mobility complexing agent. This is the case of malonic acid in the CDIIMA reaction and of ferrocyanide in the FIS reaction. In this case, it is expected that the latter species could be replaced by other proton consuming substrates. The lessons we have learned from the study of these two systems should lead the way to discovering stationary and nontrivial front dynamic patterns other than excitability waves in chemically different systems in the near future.

\section{ACKNOWLEDGMENTS}

We thank J. Boissonade and P. Borckmans for stimulating discussions. I.S. acknowledges the support of OTKA (F049666, K67701) and the MTA Bolyai Fellowship. P.D.K. is supported by CNRS and the French Agence Nationale de la Recherche.

${ }^{1}$ A. Turing, Philos. Trans. R. Soc. London, Ser. A 237, 37 (1952).

${ }^{2}$ H. Meinhardt, Models of Biological Pattern Formation (Academic, London, 1982).

${ }^{3}$ J. D. Murray, Mathematical Biology (Springer, Berlin, 2004).

${ }^{4}$ Oscillations and Traveling Waves in Chemical Systems, edited by R. J. Field and M. Burger (Wiley, New York, 1985).

${ }^{5}$ Chemical Patterns and Waves, edited by R. Kapral and K. Showalter (Kluwer Academic, Amsterdam, 1995).

${ }^{6}$ I. R. Epstein and J. Pojman, An Introduction to Nonlinear Chemical Dynamics (Oxford University Press, New York, 1998).

${ }^{7}$ Z. Noszticzius, W. Horsthemke, W. D. McCormick, H. L. Swinney, and W. Y. Tam, Nature 329, 619 (1987).

${ }^{8}$ V. Castets, E. Dulos, J. Boissonade, and P. De Kepper, Phys. Rev. Lett. 64, 2953 (1990).

${ }^{9}$ K. J. Lee, W. D. McCormick, Q. Ouyang, and H. L. Swinney, Science 261, 192 (1993).

${ }^{10}$ K. J. Lee, W. D. McCormick, J. E. Pearson, and H. L. Swinney, Nature 369, 6477 (1994).

${ }^{11}$ J. Boissonade, E. Dulos, F. Gauffre, M. N. Kuperman, and P. De Kepper, Faraday Discuss. 120, 353 (2001).

${ }^{12}$ Z. Virányi, I. Szalai, J. Boissonade, and P. De Kepper, J. Phys. Chem. A 111, 8090 (2007).

${ }^{13}$ I. Szalai and P. De Kepper, Phys. Chem. Chem. Phys. 8, 1105 (2006).

${ }^{14}$ A. Hagberg and E. Meron, Chaos 4, 477 (1994); C. Elphick, A. Hagberg, and E. Meron, Phys. Rev. E 51, 3052 (1995).

${ }^{15}$ H. Ikeda, M. Mimura, and Y. Nishiura, Nonlinear Anal. Theory, Methods Appl. 13, 507 (1989).

${ }^{16}$ S. Ponce Dawson, M. V. D'Angelo, and J. E. Pearson, Phys. Lett. A 265 , 346 (2000).

${ }^{17}$ I. Lengyel and I. R. Epstein, Proc. Natl. Acad. Sci. U.S.A. 89, 3977 (1992).

${ }^{18}$ J. E. Pearson and W. J. Bruno, Chaos 2, 513 (1992).

${ }^{19}$ V. K. Vanag and D. V. Boulanov, J. Phys. Chem. 98, 1449 (1994).

${ }^{20}$ V. Vanag and I. R. Epstein, Phys. Rev. Lett. 87, 228301 (2001); Science 294, 835 (2001); Proc. Natl. Acad. Sci. U.S.A. 100, 14635 (2003); I. R. Epstein and V. K. Vanag, Chaos 15, 047510 (2005).

${ }^{21}$ I. Szalai and P. De Kepper, J. Phys. Chem. A 108, 5315 (2004).
${ }^{22}$ P. De Kepper, I. R. Epstein, K. Kustin, and M. Orbán, J. Phys. Chem. 86, 170 (1982).

${ }^{23}$ I. Lengyel and I. R. Epstein (Ref. 5), pp. 297-322.

${ }^{24}$ J. J. Perraud, K. Agladze, E. Dulos, and P. De Kepper, Physica A 188, 1 (1992).

${ }^{25}$ B. Rudovics, E. Barillot, P. W. Davies, E. Dulos, J. Boissonade, and P. De Kepper, J. Phys. Chem. 103, 1790 (1999).

${ }^{26}$ P. W. Davies, P. Blanchedeau, E. Dulos, and P. De Kepper, J. Phys. Chem. 102, 8236 (1998).

${ }^{27}$ I. R. Epstein and I. Lengyel, Physica D 84, 1 (1995).

${ }^{28}$ Q. Ouyang, Z. Nosticzius, and H. L. Swinney, J. Chem. Phys. 96, 6773 (1992).

${ }^{29}$ E. Dulos, P. Davies, B. Rudovics, and P. De Kepper, Physica D 98, 53 (1996); B. Rudovics, E. Dulos, and P. De Kepper, Phys. Scr., T T67, 43 (1996)

${ }^{30}$ J. J. Perraud, A. De Wit, E. Dulos, P. De Kepper, G. Dewel, and P. Borckmans, Phys. Rev. Lett. 71, 1272 (1993); P. De Kepper, J. J. Perraud, B. Rudovics, and E. Dulos, Int. J. Bifurcation Chaos Appl. Sci. Eng. 4, 1215 (1994).

${ }^{31}$ D. G. Míguez, S. Alonso, A. P. Munuzuri, and F. Sagués, Phys. Rev. Lett. 97, 178301 (2006).

${ }^{32}$ Q. Ouyang, G. H. Gunaratne, and H. L. Swinney, Chaos 3, 707 (1993); A K. Horváth, M. Dolnik, A. P. Munuzuri, A. M. Zhabotinsky, and I. R. Epstein, Phys. Rev. Lett. 83, 2950 (1999); I. Berenstein, M. Dolnik, A. M. Zhabotinsky, and I. R. Epstein, J. Phys. Chem. 107, 4428 (2003); I. Berenstein, Y. Lingfa, M. Dolnik, A. M. Zhabotinsky, and I. R. Epstein, Phys. Rev. Lett. 91, 058302 (2003).

${ }^{33}$ E. C. Edblom, M. Orbán, and I. R. Epstein, J. Am. Chem. Soc. 108, 2826 (1986)

${ }^{34}$ E. C. Edblom, L. Györgyi, M. Orbán, and I. R. Epstein, J. Am. Chem. Soc. 109, 4876 (1987).

${ }^{35}$ V. Gáspár and K. Showalter, J. Am. Chem. Soc. 109, 4869 (1987); J. Phys. Chem. 94, 4973 (1990).

${ }^{36}$ G. Rábai, A. Kaminaga, and I. Hanazaki, J. Phys. Chem. 99, 9795 (1995)

${ }^{37}$ K. J. Lee and H. L. Swinney, Phys. Rev. E 51, 1899 (1995).

${ }^{38}$ G. Li, Q. Ouyang, and H. L. Swinney, J. Chem. Phys. 105, 10830 (1996).

${ }^{39}$ I. Szalai and P. De Kepper, J. Phys. Chem. A 112, 783 (2008).

${ }^{40}$ D. Horváth and Á. Tóth, J. Chem. Phys. 108, 1447 (1998); É. Jakab, D. Horváth, Á. Tóth, J. H. Merkin, and S. K. Scott, Chem. Phys. Lett. 342, 317 (2001).

${ }^{41}$ I. Szalai, F. Gauffre, V. Labrot, J. Boissonade, and P. De Kepper, J. Phys. Chem. A 109, 7843 (2005).

${ }^{42}$ T. Tanaka, D. Fillmore, S. T. Sun, I. Nishio, G. Swislaw, and A. Shah, Phys. Rev. Lett. 45, 1636 (1980).

${ }^{43}$ S. R. Sandler and W. Karo, Polymer Synthesis (Academic, New York, 1977), Vol. II.

${ }^{44}$ P. Blanchedeau and J. Boissonade, Phys. Rev. Lett. 81, 5007 (1998).

${ }^{45}$ J. Boissonade and P. De Kepper, J. Phys. Chem. 84, 501 (1980).

${ }^{46}$ U. Middiya and D. Luss, J. Phys. Chem. 102, 5029 (1995).

${ }^{47}$ P. Blanchedeau, J. Boissonade, and P. De Kepper, Physica D 147, 283 (2000).

${ }^{48}$ V. Labrot, A. Hochedez, P. Cluzeau, and P. De Kepper, J. Phys. Chem. A 110, 14043 (2006).

${ }^{49}$ J. Boissonade, P. De Kepper, F. Gauffre, and I. Szalai, Chaos 16, 037110 (2006).

${ }^{50}$ C. B. Muratov and V. V. Osipov, Phys. Rev. E 54, 4860 (1996).

${ }^{51}$ The Aldrich company indicates an electroendosmosis value of $\sim 0.13$ for the BioChemika 05070 agarose used in this work, due probably to residual charges coming from traces of agaropectin compounds.

${ }^{52}$ D. E. Strier and S. Ponce Dawson, Phys. Rev. E 69, 066207 (2004).

${ }^{53}$ J. Horvath (unpublished). 